\title{
The Clinical Course of Patients With Atrial Septal Defects
}

\author{
Mostafa Behjati-Ardakani, ${ }^{1}$ Mohammad Golshan, ${ }^{2}$ Sedigheh Akhavan-Karbasi, ${ }^{3}$ Seyed-Masood \\ Hosseini, ${ }^{3}$ Mohammad-Amin Behjati-Ardakani, ${ }^{3}$ and Mohammadtaghi Sarebanhassanabadi ${ }^{1,}$ \\ ${ }^{1}$ Yazd Cardiovascular Research Center, Shahid Sadoughi University of Medical Sciences, Yazd, IR Iran \\ ${ }^{2}$ Department of Medicine, Islamic Azad University, Yazd Branch, Yazd, IR Iran \\ ${ }^{3}$ Shahid Sadoughi University of Medical Sciences, Yazd, IR Iran \\ "Corresponding author: Mohammadtaghi Sarebanhassanabadi, Yazd Cardiovascular Research Center, Afshar Hospital, Yazd, IR Iran. Tel: +98-3535231421, Fax: +98-3535253335, \\ E-mail: mtsareban@gmail.com
}

Received 2015 November 08; Revised 2016 January 24; Accepted 2016 March 14.

\begin{abstract}
Background: Atrial septal defect (ASD) is a common congenital heart disease.

Objectives: The aim of this study was to assess the clinical course of ASD, as well as its frequency of spontaneous closure and regression of diameter.

Methods: In a study conducted from 2000 to 2011, 192 consecutive patients with an isolated ASD were followed up regularly with periodic echocardiographic evaluations according to a standardized protocol. The study was conducted in two series of patients: infants and children and adults. Infants were classified into three groups based on ASD diameter: small ( $\leq 5$ mm), medium ( 6 - 9 $\mathrm{mm})$, and large $(>9 \mathrm{~mm})$. In the same manner, the ASD size in children and adults was categorized into three groups: small $(\leq 10)$, medium $(10-20 \mathrm{~mm})$, and large $(>20 \mathrm{~mm})$.

Results: The patients consisted of 76 (39.6\%) males and 116 (60.4\%) females. The mean age of patients at diagnosis was $16.12 \pm 15.66$ years (range 1 week - 75 years). The mean follow-up duration was $70 \pm 9$ months (range: 25 - 119 months). The most prevalent age group was adult patients (> 20 years), and most ASDs were of medium size $(1-2 \mathrm{~cm})$. The most common complication was mild pulmonary hypertension (31 cases, $16.2 \%$ ), and Eisenmenger phenomenon was the rarest complication ( 2 cases, $1 \%$ ). Overall spontaneous closure of ASD occurred in 42 (21.9\%) cases. Spontaneous closure in cases with small defects occurred in 18 of 22 (81\%) infants and 24 of 81 children $>1$ years of age. Regression of ASD size occurred in 2 (9.5\%) infants and 3 (3.7\%) children. No spontaneous closure was observed in cases with a defect size $>10 \mathrm{~mm}$, and no spontaneous occlusion was detected in adolescents or adults. Seventy-two percent $(n=139)$ of patients needed surgical repair or transcatheter closure of the ASD.

Conclusions: It is concluded that atrial septal defects $<6 \mathrm{~mm}$ typically close spontaneously, and ASDs measuring 6 - $9 \mathrm{~mm}$ may regress in infants and children. An ASD $>1 \mathrm{~cm}$ has little chance of spontaneous closure and may need surgical or device closure. ASD diameter and age at diagnosis are the most important predictors of spontaneous closure and the need for possible surgical or device closure.
\end{abstract}

Keywords: Atrial Septal Defect, Natural Course, Clinical Course, Spontaneous Closure

\section{Background}

ASD is more common in females than in males $(1,2)$. Several studies have reported spontaneous closure of ASD. Besides the age of diagnosis, the size of the defect has been reported to be an important factor in the likelihood of spontaneous closure. The rate of spontaneous closure has been reported to range from $14 \%$ - 55\% (3). One study reported that spontaneous closure of ASDs smaller than 6 $\mathrm{mm}$ is very likely, and operative closure for defects larger than $8 \mathrm{~mm}$ has a high probability (4). Spontaneous closure does not seem to be affected by clinical signs and symptoms, because it has been reported in infants with heart failure $(3,5)$.

\section{Objectives}

The aim of this study was to determine the clinical course of ASD, its frequency of spontaneous closure, and size changes.

\section{Methods}

This was a retrospective study of consecutive infants and children with isolated ASD at a tertiary hospital. The data included patient age and sex and type, size, and complications associated with ASD. These data were collected through outpatient and hospital records. In infancy, the defects were classified as small ( $>3 \mathrm{~mm}$ to $\leq 5 \mathrm{~mm}$ ), medium ( $>5 \mathrm{~mm}$ to $9 \mathrm{~mm}$ ), and large ( $\geq 10 \mathrm{~mm}$ ). After infancy, the ASD size was interpreted as follows: less than 
$10 \mathrm{~mm}$ as small, $10-20 \mathrm{~mm}$ as medium, and larger than 20 $\mathrm{mm}$ as large. All echocardiography was performed by the same pediatric cardiologist. Subcostal four chamber and sagittal views were used to measure ASD size. For statistical analysis, the chi-square test and Fisher's exact test were used, and P values $<0.05$ was taken as significant.

\section{Results}

Among 2,200 cases of congenital heart disease, 216 (9.8\%) patients suffered from ASD. Twenty four patients with incomplete data were excluded from the study. The study cases consisted of 116 (60.4\%) females and 76 (39.6\%) males. The mean age at diagnosis was $16.12 \pm 15.66$ years (range: 1 week - 75 years). The mean follow-up duration was $70 \pm 9$ months (range: 25 - 119 months). Among 192 ASD patients, 22 cases were infants, 81 were children, 25 were adolescents, and 64 were adults. Approximately 93.2\% of ASD cases were of the simple secundum type, $2.6 \%$ were primary, $1.6 \%$ were sinus venous, and $2.6 \%$ were a combination of different ASD types.

Table 1 indicates the frequency of ASD complications in different age groups. It is shown that the most common complication was pulmonary arterial hypertension, and Eisenmenger phenomenon was the least common complication. As is clear from Table 1, most complications were related to medium and large defects. Table 2 depicts the frequency of ASD size in different age groups as follows: small ASD primarily occurred in infants, medium ASD in children, and large ASD in adults.

Table 3 shows the distribution of the type of closure of atrial defect related to age group. It can be seen that spontaneous closure occurred in infancy and childhood. Table 4 shows the frequency of spontaneous closure of ASD in different age groups.

\section{Discussion}

The highest number of spontaneous ASD closures occurred in patients younger than 2 years. This finding did not support the role of age in closure because ASD size played the main role in spontaneous closure. Spontaneous closure of medium and large ASDs did not occur, and the defect was recognized in older ages. In the current study, ASD constitutes $9.8 \%$ of congenital anomalies, which is comparable to the results of other studies. The ratio of female to male patients in this study was 1:5, which is lower than that in some studies (2) but in closer agreement with other reports $(1,6)$.

Among 22 cases of small ASD, 81\% closed during infancy. This result is higher than that of studies that reported spontaneous closure rates of $14 \%-55 \%(3,7)$, but concurrent with studies reporting closure rates of $66 \%$ $92 \%$ (8).

In this study, the overall prevalence rate of hypertension in the pulmonary artery was $16.2 \%$, and its incidence increased with increasing age among the four age groups. Its incidences in infants, children, adolescents, and adults were zero, $6.2,16$, and $34.2 \%$, respectively. In another study, the risk of moderate to severe pulmonary hypertension in adults was reported as $27 \%$ (9). Therefore, aging can be an important factor influencing the high incidence of pulmonary arterial hypertension. Furthermore, pulmonary hypertension in adult patients in the current study was higher than in other studies, which may be due to delays in diagnosis or referral.

In our study, spontaneous closure occurred only during infancy and childhood. However, in adolescence and adulthood, no spontaneous closure was observed. Therefore, ASD in adolescents and adults should be followed up and if necessary repaired surgically or with transcatheter intervention. In our study, reduction in the size of ASD occurred in $12.7 \%$ of infants and children with an ASD size of less than $9 \mathrm{~mm}$. In this respect, McMahon et al. have reported a result of $14 \%$ (9).

The median age of the patients with spontaneous closure was 2.25 years, and the maximum age at spontaneous closure was 3.9 years. Our study confirmed previous reports $(10,11)$ indicating that spontaneous closure can occur beyond infancy. Therefore, the window of opportunity for selective surgery can be determined according to patient age. None of our patients with an ASD size of $9 \mathrm{~mm}$ or less needed surgery. In our study, $72.4 \%$ of patients needed surgery or transcatheter closure, a finding similar to the results (77\%) of Hanslik et al. (10) Ozcelik et al. (11) reported no cases of spontaneous closure for $8 \mathrm{~mm}$ ASDs (12). However, in our study, 8 (4.1\%) cases of spontaneous closure of 9 $\mathrm{mm}$ ASDs occurred in childhood. Demir et al. (7) reported a spontaneous closure rate of $7.5 \%$ in $8 \mathrm{~mm}$ ASDs. Overall, it can be concluded that spontaneous closure may occur rarely in ASDs measuring 8 - $9 \mathrm{~mm}$.

Heart failure occurred in $3.1 \%$ of the cases; however, none of the heart failure cases were in infants, and most of them were in adults. In other studies, the majority of heart failure cases were also reported in patients older than 40 years $(13,14)$.

In our study, $93(48.4 \%)$ cases were closed by transcatheter and 46 (24\%) by surgery. In the transcatheter group, one case died due to anaphylactic shock caused by the contrast agent. In the surgery group, there were two cases of death due to massive pericardial effusion and chronic intractable right heart failure.

In the transcatheter group, $8.2 \%$ of patients experienced complications, and $10.4 \%$ of patients from the sur- 
Table 1. Distribution of Complications in Different Age Groups ${ }^{\mathrm{a}}$

\begin{tabular}{|c|c|c|c|c|c|}
\hline \multirow[t]{2}{*}{ Type of Complication } & \multicolumn{4}{|c|}{ Age Group } & \multirow[t]{2}{*}{ Total } \\
\hline & Infants & Children & Adolescents & Older Ages & \\
\hline Pulmonary hypertension & - & $5(6.2)$ & $4(16)$ & $22(34.4)$ & $31(16.2)$ \\
\hline Heart failure & - & - & $1(4)$ & $5(7.8)$ & $6(3.1)$ \\
\hline Eisenmenger & - & - & - & $2(3.1)$ & $2(1)$ \\
\hline Arrhythmia & - & - & - & $2(3.1)$ & $2(1)$ \\
\hline Uncomplicated & $22(100)$ & $75(92.6)$ & $18(72)$ & $29(45)$ & $144(75)$ \\
\hline Total & $22(100)$ & $81(100)$ & $25(100)$ & $64(100)$ & $192(100)$ \\
\hline
\end{tabular}

${ }^{\mathrm{a}}$ Pearson's chi-square test was used, P value $=0.001$.

Table 2. Defect Size in Different Age Groups ${ }^{\mathrm{a}}$

\begin{tabular}{|c|c|c|c|c|c|}
\hline \multirow[t]{2}{*}{ Defect Size } & \multicolumn{4}{|c|}{ Age Group } & \multirow[t]{2}{*}{ Total } \\
\hline & Infants & Children & Adolescents & Adults & \\
\hline Small & $16(72.7)$ & $7(8.6)$ & - & - & $23(12)$ \\
\hline Medium & $4(18.2)$ & $52(64.2)$ & $17(68)$ & $28(43.7)$ & $101(52.6)$ \\
\hline Great & $2(9.1)$ & $22(27.2)$ & $8(32)$ & $36(54.4 .1)$ & $36(56.3)$ \\
\hline
\end{tabular}

${ }^{\text {a }}$ Pearson's chi-square test was used, P value $=0.001$.

Table 3. Type of Closure of the Atrial Defect in Different Age Groups ${ }^{\mathrm{a}}$

\begin{tabular}{|c|c|c|c|c|c|}
\hline \multirow[t]{2}{*}{ Type of Closure } & \multicolumn{4}{|c|}{ Age } & \multirow[t]{2}{*}{ Total } \\
\hline & Infants & Childhood & Adolescents & Adults & \\
\hline Spontaneous & $18(81)$ & $24(29.6)$ & - & - & $42(21.9)$ \\
\hline Reduced size & $2(9.5)$ & $3(3.7)$ & - & - & $5(2.6)$ \\
\hline Catheterization & - & $37(45.7)$ & $18(72)$ & $38(58.4)$ & $93(48.4)$ \\
\hline No specific follow-up work & $2(9.5)$ & $3(3.7)$ & $1(4)$ & - & $6(3.1)$ \\
\hline Total & $22(100)$ & $81(100)$ & $25(100)$ & $64(100)$ & $192(100)$ \\
\hline
\end{tabular}

${ }^{\mathrm{a}}$ Pearson's chi-square test was used, $\mathrm{P}$ value $=0.001$.

gical group suffered complications. The rates of mortality and complications were not significantly different between the aforementioned groups.

In other studies, complications in the surgical group were reportedly higher than in the catheterization group (15-17). Nevertheless, many studies have reported a higher rate of success, fewer complications, and shorter hospital stays for ASD closure with an Amplatzer device (18-22). Therefore, the closure of ASD through a catheter can be considered as an alternative method of surgical repair.
In our study, $2(1 \%)$ patients had supraventricular arrhythmias, one adult patient had fibrillation, and another adult patient had an atrial flutter, indicating co-morbid condition rates similar to those found in other studies (2). It can be concluded that age is an important factor in the development of arrhythmia.

\subsection{Conclusions}

It can be concluded that babies suffering from ASDs measuring less than $5 \mathrm{~mm}$ do not require treatment be- 
Table 4. Assessing the Frequency of Spontaneous Closure of Atrial Defects in Different Age Groups

\begin{tabular}{lc}
\hline Age, $\mathbf{y}$ & No. $(\%)$ \\
\hline$<\mathbf{1}$ & $18(42.9)$ \\
\hline $\mathbf{1 . 1}-\mathbf{2}$ & $14(33.3)$ \\
\hline $\mathbf{2 . 1}-\mathbf{3}$ & $7(16.7)$ \\
\hline $\mathbf{3 . 1}$ - & $3(7.1)$ \\
\hline Total & $42(100)$ \\
\hline
\end{tabular}

cause spontaneous closure will likely occur in the first year of life. Infants with an ASD size of 5 - $9 \mathrm{~mm}$ may need echocardiography at the ages of 12 and 24 months. The probability of closure in ASDs $9 \mathrm{~mm}$ or larger is low, and parents should be reminded of the probable need for closure through surgery or catheterization. Children suffering from ASDs larger than $1 \mathrm{~cm}$ have a lower chance of spontaneous closure.

\section{Footnote}

Authors' Contribution: Study concept and design: Mostafa Behjati-Ardakani, Mohammad Golshan, Sedigheh Akhavan-Karbasi, and Seyed-Masood Hosseini; analysis and interpretation of data: M-Behjati-Ardakani; drafting of the manuscript: Mostafa Behjati-Ardakani, Mohammad-Amin Behjati-Ardakani, and Mohammadtaghi Sarebanhassanabadi; critical revision of the manuscript for important intellectual content: Mostafa Behjati-Ardakani, Mohammad Golshan, Sedigheh Akhavan-Karbasi, and Seyed-Masood Hosseini; statistical analysis: Mostafa Behjati-Ardakani and Mohammadtaghi Sarebanhassanabadi.

\section{References}

1. Amel-Shahbaz S, Behjati-Ardakani M, Namayandeh SM, Vafaeenasab M, Andishmand A, Moghimi S, et al. The epidemiological aspects of congenital heart disease in central and southern district of Iran. Adv Biomed Res. 2014;3:233. doi: 10.4103/2277-9175.145732. [PubMed: 25538919].

2. Porter CBJ, Edwards W. In: Moss and Adam's Heart Disease in infants, Children and Adolescents. Allen HD, Driscol DJ, Shaddy RE, Feltes TF, editors. Philadelphia: Lippincott William S Wilkins; 2008. pp. 63245.Atrial septal defect.

3. Mahoney LT, Truesdell SC, Krzmarzick TR, Lauer RM. Atrial septal defects that present in infancy. Am J Dis Child. 1986;140(11):1115-8.

4. Helgason H, Jonsdottir G. Spontaneous closure of atrial septal defects. Pediatr Cardiol. 1999;20(3):195-9. doi: 10.1007/s002469900439. [PubMed: 10089243].

5. Mody MR. Serial hemodynamic observations in secundum atrial septal defect with special reference to spontaneous closure. Am J Cardiol. 1973;32(7):978-81. [PubMed: 4757238].
6. Bostan OM, Cil E, Ercan I. The prospective follow-up of the natural course of interatrial communications diagnosed in 847 newborns. Eur Heart J. 2007;28(16):2001-5. doi:10.1093/eurheartj/ehm268. [PubMed: 17623678].

7. Demir T, Oztunc F, Eroglu AG, Saltik L, Ahunbay G, Kutlug S, et al. Outcome for patients with isolated atrial septal defects in the oval fossa diagnosed in infancy. Cardiol Young. 2008;18(1):75-8. doi: 10.1017/S1047951107001692. [PubMed: 18179730].

8. Radzik D, Davignon A, van Doesburg N, Fournier A, Marchand T, Ducharme G. Predictive factors for spontaneous closure of atrial septal defects diagnosed in the first 3 months of life. J Am Coll Cardiol. 1993;22(3):851-3. [PubMed: 8354823].

9. McMahon CJ, Feltes TF, Fraley JK, Bricker JT, Grifka RG, Tortoriello TA, et al. Natural history of growth of secundum atrial septal defects and implications for transcatheter closure. Heart. 2002;87(3):256-9. [PubMed: 11847166].

10. Hanslik A, Pospisil U, Salzer-Muhar U, Greber-Platzer S, Male C. Predictors of spontaneous closure of isolated secundum atrial septal defect in children: a longitudinal study. Pediatrics. 2006;118(4):1560-5. doi: 10.1542/peds.2005-3037. [PubMed: 17015547].

11. Ozcelik N, Atalay S, Tutar E, Ekici F, Atasay B. The prevalence of interatrial septal openings in newborns and predictive factors for spontaneous closure. Int J Cardiol. 2006;108(2):207-11. doi: 10.1016/j.ijcard.2005.05.023. [PubMed: 16002166].

12. Craig RJ, Selzer A. Natural history and prognosis of atrial septal defect. Circulation. 1968;37(5):805-15. [PubMed: 5646864].

13. Gault JH, Morrow AG, Gay WA, Ross J. Atrial septal defect in patients over the age of forty years clinical and hemodynamic studies and the effects of operation. Circulation. 1968;37(2):261-72.

14. Thomson JD, Aburawi EH, Watterson KG, Van Doorn C, Gibbs JL. Surgical and transcatheter (Amplatzer) closure of atrial septal defects: a prospective comparison of results and cost. Heart. 2002;87(5):466-9. [PubMed: 11997423].

15. Du ZD, Hijazi ZM, Kleinman CS, Silverman NH, Larntz K. Comparison between transcatheter and surgical closure of secundum atrial septal defect in children and adults: results of a multicenter nonrandomized trial. J Am College Cardiol. 2002;39(11):1836-44.

16. Butera G, Carminati M, Chessa M, Youssef R, Drago M, Giamberti A et al. Percutaneous versus surgical closure of secundum atrial septal defect: comparison of early results and complications. Am Heart J. 2006;151(1):228-34. doi:10.1016/j.ahj.2005.02.051. [PubMed:16368323].

17. Knepp MD, Rocchini AP, Lloyd TR, Aiyagari RM. Long-term follow up of secundum atrial septal defect closure with the amplatzer septal occluder. Congenit Heart Dis. 2010;5(1):32-7. doi: 10.1111/j.17470803.2009.00358.x. [PubMed: 20136855].

18. Al'dzhammaz K, Borisova NA, Aleksandrov K, Il'in AS, Tsytko AL. [Results of transcatheter closure of the secundum atrial septal defects in children]. Vestn Khir Im II Grek. 2008;167(5):51-4. [PubMed: 19069823].

19. Behjati M, Mirhosseini SJ, Hosseini SH, Rajaei S. Transcatheter Closure of Atrial Septal Defect with Amplatzer Device in Children and Adolescents: Short and Midterm results; an Iranian Experience. Iran J Pediatr. 2011;21(2):166-72. [PubMed: 23056783].

20. Majunke N, Bialkowski J, Wilson N, Szkutnik M, Kusa J, Baranowski A, et al. Closure of atrial septal defect with the Amplatzer septal occluder in adults. Am J Cardiol. 2009;103(4):550-4. doi: 10.1016/j.amjcard.2008.10.018. [PubMed: 19195519].

21. Wilson NJ, Smith J, Prommete B, O'Donnell C, Gentles TL, Ruygrok PN Transcatheter closure of secundum atrial septal defects with the Amplatzer septal occluder in adults and children-follow-up closure rates, degree of mitral regurgitation and evolution of arrhythmias. Heart Lung Circ. 2008;17(4):318-24. doi: 10.1016/j.hlc.2007.10.013. [PubMed: 18407789].

22. Behjati M, Rafiei M, Soltani MH, Emami M, Dehghani M. Transcatheter closure of atrial septal defect with amplatzer septal occluder in adults: immediate, short, and intermediate-term results. $J$ Tehran Heart Cent. 2011;6(2):79-84. [PubMed: 23074610]. 